\title{
AS PAIXÕES EM PLUTARCO: O PAPEL DO SILÊNCIO NA CURA DA TAGARELICE
}

\author{
THE PASSIONS IN PLUTARCH: THE ROLE OF SILENCE IN THE HEALING OF CHATTER
}

Vanderley Nascimento Freitas*

\section{RESUMO}

Plutarco de Queroneia (45-125), maior expoente do médio platonismo, é autor de uma vasta obra, cujos textos conservados foram divididos em dois grandes grupos, as Vidas paralelas (Bioi Paralleloi) e as Obras morais (Moralia). Interessa-nos aqui examinar os vários âmbitos em que é possível reconhecer uma reflexão acerca das paixões em Plutarco, inserindo-a na busca pela boa vida preconizada pelo filósofo, a fim de evidenciar os caminhos para a cura de um páthos em particular: a tagarelice. No presente artigo, examinaremos mais de perto quatro tratados do corpus de Plutarco, a saber, Sobre a tagarelice, Como ouvir, O banquete dos sete sábios e Das doenças da alma e do corpo: quais as mais nefastas? Entrevendo o horizonte do bem viver, buscaremos mostrar como o filósofo faz com que o silêncio emerja como um ingrediente particular ao se pensar no tratamento de uma alma flagelada pelas paixões. Buscaremos, ainda, trazer à luz as fontes do pensamento antigo nas quais Plutarco se inspira, sobretudo no que diz respeito ao tema relacionado às paixões.

PALAVRAS CHAVE: Plutarco. Paixões. Ética. Silêncio. Alma.

\section{ABSTRACT}

Plutarch of Chaeronea (45-125), the highest exponent of Middle Platonism, is the author of a vast work, whose conserved texts were divided into two great groups, the Parallel lives (Bioi Paralleloi) and the Moral works (Moralia). We are here interested in examine the various fields in which it is possible to recognize a reflection upon the passions in Plutarch, inserting it in the search for the good life recommended by the philosopher, in order to highlight the ways for the healing of a particular pathos: the chatter. In the present article, we will look over more closely four treatises on Plutarch's corpus, namely, On talkativeness, On listening to lectures, Dinner of the seven wise men and Whether the affections of the soul are worse than those of the body. Glimpsing the horizon of well-being, we shall try to show how the philosopher makes silence emerge as a particular ingredient in thinking about the treatment of a soul plagued by passions. We will also try to bring to light the sources of ancient thought in which Plutarch inspired himself, above all regarding the theme related to the passions.

KEYWORDS: Plutarch. Passions. Ethic. Silence. Soul.

Definido por Montaigne como "o autor mais judicioso do mundo" (le plus judicieux auteur du monde), Plutarco foi um filósofo e biógrafo grego nascido na Queroneia, região da Beócia, que viveu em um mundo já dominado pelo império romano; estudou na célebre academia de Platão em Atenas, onde teve contato com o peripatético Amônio. Viajou pelo Egito

\footnotetext{
* Mestre e doutorando em Filosofia pela Universidade Federal de Minas Gerais. E-mail: e-maildoautor@gmail.com.
} 
e Ásia e, devido a seu prestígio, obteve título de cidadão em Roma, Atenas e Delfos. Inserido na tradição do chamado médio-platonismo, será um verdadeiro polígrafo, possuindo uma das obras mais significativas do período, não apenas pela quantidade, que lidera, mas pela qualidade dos escritos filosóficos que, além de nos apresentar as posições filosóficas de uma época já tributária de Platão, Aristóteles e das escolas do helenismo, nos coloca diante de sua própria filosofia. Sua obra é dividida em dois grupos: Vidas paralelas e Moralia. Nas Vidas, o Queronense expõe a vida de homens ilustres tomando-os dois a dois, um grego e um romano, a fim de colocar em jogo os vícios e virtudes dos biografados, realizando ao fim uma comparação (synkresis) ${ }^{1}$ das duas personagens em questão. A Moralia, por sua vez, reúne um grande número de tratados, de menor ou maior extensão, nos quais se ocupa de temas pertinentes aos mais diversos âmbitos da especulação filosófica: ética, religião, retórica, astronomia, política e crítica literária ${ }^{2}$. Embora seja a Moralia a parte de sua obra de que em geral se ocupam os historiadores da filosofia, não se deve negligenciar o fundo filosófico subjacente à "costura" de natureza ético-antropológica das Vidas. Com efeito, essas não são uma mera exposição biográfica de fatos e feitos, mas constituem um sub-reptício exame crítico dos vícios e virtudes do biografado, com o intuito de suscitar em seu leitor uma reflexão sobre o seu próprio modus vivendi. ${ }^{3}$ Há de se nuançar, ainda, a sua inegável contribuição para o conhecimento posterior da cultura greco-romano, da qual é fonte recorrente. Seus escritos, com forte apelo ético, seduziram mentes como as de Espinosa, Voltaire e Montaigne, além do dramaturgo Shakespeare.

O ambiente cultural e filosófico a que pertence Plutarco viria, posteriormente, a receber a alcunha de "médio platonismo", referindo-se ao movimento representado por uma aquarela de pensadores que antecederam o neoplatonismo e a síntese de Plotino. Como uma marca importante dos médio-platônicos, temos a tentativa de conciliação das doutrinas de Platão e daquelas de seu discípulo, Aristóteles; tentativa esta que, observados certos limites, encontrará

\footnotetext{
${ }^{1}$ Sobre as comparações, Russell entende que se trata de uma escolha retórica de Plutarco, que reproduz um exercício comum nas escolas da época "Você ouviu duas histórias, quais os pontos de similaridade e diferença você percebe? [...] Qual é o melhor homem e qual o pior?” (tradução nossa) (RUSSELL, 1972, p. 110).

${ }^{2}$ De acordo com o levantamento do especialista Ziegler (1965, p. 84), excluindo-se aquilo que provavelmente é apócrifo, Plutarco escreveu 250 obras com cerca de 300 livros.

${ }^{3}$ No prefácio à sua tradução das Vidas paralelas, Anne-Marie Ozanam observa que se para Plutarco "viver é saber contemplar", o seu repertório das Vidas/Bioi se apresenta como "um espetáculo dentro do espetáculo, que tem a propriedade de suscitar instantaneamente o desejo de imitação" (OZANAM, 2001, p. 20). Desse se aproxima o juízo de V. Schilling: "ao contrário de Suetônio (60 -120), o ligeiro biógrafo dos Césares (Vida dos Doze Césares), que pinçou atos bizarros dos imperadores, traçando caricaturas de alguns deles, Plutarco, seu contemporâneo, optou pela relevância dos seus retratados. Tinha a firme convicção didática de que a virtude era um atributo a ser imitado, seguido por qualquer pessoa de boa vontade. Acreditava, como Aristóteles e os peripatéticos, que toda a ação é resultante de uma concepção ética que a antecede. Até as coisas negativas que os grandes cometeram podem servir para nos corrigir" (SCHILLING, 2005, p. 10).
} 
sua expressão no modo como Plutarco encaminha a sua reflexão filosófica. Tendo vivido por volta do ano 45 da era cristã até cerca de 125, Plutarco não negligenciou as doutrinas desenvolvidas no período helenístico, as quais viria muitas vezes a combater, sobretudo aquelas da tradição epicurista e, ainda com mais energia, as da escola estoica que, por ser a mais difundida e popular das escolas, representaria, por isso mesmo, um dos maiores perigos. Observa-se, então, que no confronto das doutrinas de Platão, de Aristóteles e do Estoicismo, é que vemos gestar-se e vir à luz a filosofia de Plutarco, o que justificará que busquemos, ao longo da nossa exposição, reconhecer aquelas referências e fontes antigas do pensamento grego, das quais Plutarco provavelmente retirou sua inspiração ao tratar o tema das paixões. Entre as diversas paixões que podem angariar a alma do homem, Plutarco achou prudente refletir acerca de uma em particular: a tagarelice. Contudo, se o filósofo mostrará o diagnóstico daquele que padece de tal páthos, não deixará que propor o prognóstico devido, dando atenção especial, como veremos, ao tratamento pelo silêncio.

Plutarco condicionará a eudaimonia ao modo como os homens lidam com as suas afecções, donde a importância de sua "teoria" das paixões para que se possa compreender o teor de seus escritos em que busca traçar o caminho para a boa vida. A que categoria da reflexão ética pertencem as afecções? É possível estabelecer uma medida que possibilite ao homem conviver com esse traço inato da sua natureza sem correr o risco de que elas se tornem um empecilho para a vida boa? O que difere as afecções da alma das do corpo? As afecções da dimensão somática são de mais difícil tratamento do que aquelas da psicológica? Se sim ou se não, por quê? Há algum órgão que se preste a ser a porta de entrada para a alma? Vejamos o que Plutarco nos diz a respeito.

\section{PLUTARCO E AS PAIXÕES}

$\mathrm{Na}$ etimologia dos termos páthos/pathé, que aqui traduzimos por afecção/afecções, encontra-se a ideia de "padecimento", "doença", "passividade”, "paixão", como algo que foge do devido controle e deixa o homem à mercê da fortuna, mas também a ideia de uma força vital necessária à vida humana. Conforme Reale (2001, p. 195), o termo páthos pode ser mais bem traduzido por "paixão", ao designar propriamente uma perturbação da alma, mas também pode ser traduzido por afecção, cuja definição, seguindo o itinerário de Reale, nos é dada pela Metafísica de Aristóteles (Metafísica, V, 21, 1022b 15-22): 
Afecção significa, em primeiro lugar, uma qualidade segundo a qual a coisa pode alterar-se: por exemplo, o branco e o negro, o doce e o amargo, o pesado e o leve, e todas as outras qualidades deste tipo. Num outro sentido, afecção significa a atuação dessas alterações, ou seja, a alteração já em ato. Além disso, chamam-se afecção especialmente as alterações e mudanças danosas, sobretudo os danos que produzem dor. Enfim, chamam-se afecções as grandes desgraças e as grandes dores.

$\mathrm{Na}$ definição do termo, então, o estagirita reconhece que, em um sentido, determinadas coisas possuem a potência de alternarem-se de um estado a outro, como que por acidente. Depois, Aristóteles identifica no ato mesmo da mudança de um estado a outro o momento que chama de "afecção". Por fim, ele apresenta o sentido de afecção que mais se aproxima deste nosso trabalho: aquele em que a afecção diz respeito às mudanças de estado nas quais se observa um dano, levando inclusive à dor, neste sentido podemos colocar não apenas as afecções que alteram o estado de saúde do corpo, mas também aquele da alma. Ao observar como o termo aparece em Plutarco e as opções de diversos tradutores, parece-nos melhor, então, usar "afecção" de modo geral para se referir tanto a uma alteração no corpo, quanto na alma e, no caso específico do uso do termo "paixão", a uma alteração própria da alma.

Portanto, as afecções devem ser abordadas discriminando que se trata de um evento que ocorre na psychê em detrimento das afecções que também assolam o corpo. A este propósito, examinemos aqui um trecho do Timeu ${ }^{4}$ de Platão em que encontramos uma análise das afecções. Após efetuar a descrição de algumas doenças que afetam o corpo e suas causas, Timeu passa a tratar das particularidades das doenças que afetam a alma, mas sem isolar o corpo, que padece em sintonia com alma, cujos distúrbios se seguem da condição somática do indivíduo:

Os [distúrbios] que afetam a alma, e que resultam da condição do corpo, ocorrem do modo que se segue. Temos que admitir que a doença da alma é a demência, e há dois géneros de demência: a loucura e a ignorância. A todas as impressões que alguém sofra e que englobem uma das duas devemos chamar "doença". Devemos também estabelecer que os prazeres e as dores em excesso são as mais graves das doenças para a alma. É que quando um homem está excessivamente contente ou, pelo contrário, sofre por causa da dor, apressando-se a arrebatar inoportunamente algum objeto ou a fugir do outro, não é capaz de ver nem de ouvir nada corretamente, pois está louco e a sua capacidade de participar do raciocínio encontra-se reduzida ao mínimo. (Timeu, 86B-C).

\footnotetext{
${ }^{4}$ A propósito, um traço comum à seara de filósofos do médio-platonismo foi comentar o diálogo Timeu. Reale (2008, p. 277) observa que "na difícil tarefa de reduzir a filosofia platônica a sistema e na tentativa de fazer uma síntese dela, o Timeu era o diálogo que oferecia a trama mais sólida. É interessante observar, a propósito disso, que os médio-platônicos seguiram preferencialmente um método oposto ao dos peripatéticos dessa época (de Andrônico a Alexandre): de fato, os primeiros consideraram que a melhor forma de compreender Platão era compendiá-lo. Os segundos, ao invés, consideraram que o melhor modo de compreender Aristóteles era comentá-lo." De fato, no que diz respeito aos compêndios, é este o caso de expoentes do médio-platonismo como Albino e seu Didaskalikos, mas, sublinhamos, não parece ser exatamente o caso de Plutarco, em que o comentário também tem lugar.
} 
Todos os distúrbios que afetam a alma, sejam do gênero da loucura, sejam da demência, devem-se denominar "pathê", porém, Timeu pontua que, entre as várias doenças que podem acometer a psychê, as mais nefastas serão aquelas nas quais não somente a dor mas também o prazer $^{5}$ ocorrerem de maneira desmedida. Acentua-se que esse estado de excesso não lhe permite fazer o correto uso dos sentidos, como ver e ouvir, traduzindo na debilidade da sua capacidade de aceder à razão. Seria, então, as pathé, um fator determinante que impediria ao homem de racionar devidamente? $\mathrm{E}$ a falta de harmonia decorrente dos excessos de dor ou de prazer seria a causa de tal estado de espírito?

No âmbito helenístico, tendo a escola estoica perdurado por tantos anos e encontrado uma série de formulações de suas teses principais, as teorias acerca das paixões receberam formulações diversas ao longo do tempo (GAZOLLA, 1999, p. 127-171). Emerge no estoicismo o conceito de apatheia, para designar o estado de imperturbabilidade da alma, que não se deixa abater pelas paixões. O filósofo da Queroneia buscará combater esse ideal de apatheia, bem como flagrar, a partir de sua economia das paixões, pontos ilógicos na doutrina estoica. As polêmicas são diversas, mas Plutarco, severo crítico da filosofia do Pórtico, não foi o único a apontar as contradições nas doutrinas estoicas. Entre os próprios membros da escola, as visões apresentavam divergências. É o caso, por exemplo, das ideias do Estoico Possidônio que, de acordo com o que Galeno nos legou em seu Preceitos de Hipócrates e Platão (De plac. Hipp, et Plat., V, 6, p. 448), teria nestes termos criticado Crisipo:

\begin{abstract}
A causa das paixões e, portanto, de uma vida incoerente e infeliz, é não seguir em tudo o daimôn que lhe é congênito e que tem a mesma natureza de quem rege todo o universo, mas deixar-se levar, consentindo no pior e no apetite animalesco. Mas eles, os seguidores de Crisipo, ignorando isso, não dão nesse campo uma razão melhor para as paixões, nem pensam retamente sobre a felicidade e sobre o acordo com a natureza. De fato, não veem que nela, antes de tudo, trata-se de não se deixar arrastar pelo que de irracional, maléfico e ateu existe na alma. (Apud CHAUÍ, 2010, p. 184).
\end{abstract}

O que o homem precisaria priorizar, então, é a sua razão, o daimôn aqui evocado por Possidônio, e caso essa recomendação não seja seguida o homem estará sujeito às paixões e distante da boa vida. Trata-se de uma crítica à tese de Crisipo segundo a qual não haveria uma parte irracional na alma, e as paixões seriam o mero produto de um juízo errôneo da razão.

\footnotetext{
${ }^{5}$ No caso do Filebo, prazer e dor estarão ligados à existência da harmonia. Maciel discorre que "quando a harmonia se dissolve (luoménes) (31D4), tem-se logo a dissolução da natureza gerando dor; quando a harmonia se restabelece, obtém-se prazer. Todavia, para o prazer e a dor, que surgem como eco de afecções corporais, existe uma outra possibilidade, uma outra espécie (eídos): a alma sozinha pode prevê-las, é a expectativa (prosdóchema) dessas afecções (pathémata) que podem ser experimentadas como esperança do estado prazeroso ou temor do estado doloroso (32C)." (MACIEL, 2003, p. 191).
} 
Assim, polemizando com pensadores do pórtico, escreverá Plutarco em seu Da virtude moral acerca da doutrina das paixões do estoico Crisipo:

\begin{abstract}
Alguns sustentam que a paixão não é essencialmente diferente da razão e que entre as duas não há diferença e contraste, mas a mesma razão desenvolve-se em ambas, o que nos escapa pela rapidez e velocidade da mudança: não nos damos conta, com efeito, de que é a mesma parte da alma que, por sua natureza, deseja e se arrepende, irrita-se e teme, é movida do prazer ao que é torpe e, de novo, enquanto é movida, se detém. De fato, desejo, ira, temor e todos os outros sentimentos semelhantes são opiniões e juízos depravados, que não nascem de nenhuma das duas partes da alma, mas são inclinações, concessões, assentimentos e impulsos da parte que dirige e, em poucas palavras, forças que facilmente mudam, assim como a impetuosidade das crianças, cujo furor e a violência são instáveis e inconstantes pela sua fragilidade. (Virt. Mor. 446F, tradução nossa).
\end{abstract}

Nota-se o tom irônico com que Plutarco expõe o pensamento de Crisipo, criticando a tese da paixão como fruto de um juízo da razão, o que entenderia como uma coincidência entre logos e páthos ${ }^{6}$. Tratar-se-ia de uma crítica à tese intelectualista das paixões de Crisipo. Como assinalamos antes, Plutarco combate veementemente o ideal estoico da apatheia, que advoga a necessidade de não se deixar abater pelas paixões; ao contrário deles, o Queronense irá defender com caminho viável e possível, aquele da moderação das paixões, uma vez que elas, as paixões, são parte integrante da natureza humana e como tais não devem ser objeto de uma total supressão, mas de um controle. E qual, afinal, seria o estatuto das paixões em Plutarco? Qual a sua relevância no âmbito da reflexão ética?

Uma pista para responder a tais indagações podemos encontrar em seu emblemático Das doenças da alma e do corpo: quais as mais nefastas? (Animine an corporis affectiones sint peiores). Como o próprio título do tratado sugere, Plutarco pretende verificar, entre as afecções que afetam o corpo e as que afetam a alma, quais trariam os maiores prejuízos para a vida do homem. Considerando que o homem é entre os animais o que mais estaria sujeito a males ${ }^{7}$, Plutarco deseja agora examiná-los isoladamente, sem compará-lo com outros animais. Para tanto, estabelece um paralelo entre as doenças psíquicas e as corpóreas. Partindo do pressuposto de que as doenças do corpo ocorrem por acidente e que as doenças da psychê têm origem nela mesma, Plutarco defenderá a tese de que estas são as mais nefastas para o corpo. Mas por que as considera assim? Na justificativa que apresentará Plutarco, vemos se desenhar mais um traço de sua filosofia, traço que será um topos recorrente na sua reflexão ética:

\footnotetext{
${ }^{6}$ Também em Sêneca (1977, livro III-8) encontramos tal identificação de páthos e logos: “a paixão e a razão não ocupam lugares particulares e separados, são apenas modificações do espírito, para o bem e para o mal”.

${ }^{7}$ A referência é a Ilíada de Homero (17, 446-447), na qual lemos que "nenhum [animal] é mais miserável que o homem, de tudo que sobre a terra respira ou se move".
} 
Ó homem, também em ti o corpo produz naturalmente, por si mesmo, muitas doenças e afecções e recebe tantas outras que chegam de fora; mas se te abrires a ti mesmo para dentro, encontrarás como que um depósito variegado de males múltiplos em afecções, um verdadeiro tesouro, como diz Demócrito ${ }^{8}$, de coisas que não afluem do exterior, mas que têm, por assim dizer, fontes subterrâneas e autóctones que o vício faz jorrar com abundância e prodigalidade nas afecções. (An. corp. affect. pei. 500D-E).

Plutarco confere às doenças do corpo certa autonomia, como se elas estivessem numa esfera cuja ocorrência das pathé muitas vezes não depende de nós, oriundas da natureza mesma do corpo, as pathé não apenas advém da fortuna da particularidade biológica de cada um, como muitas vezes se apoderam do homem de modo externo, refletindo a submissão humana em relação ao padecer do corpo. De fato, doenças congênitas ou alguma fratura, por exemplo, são enfermidades que assolam o corpo para além do controle dos homens, deixando-os à mercê da sorte. Mas se são diversas as doenças que atingem o corpo, maiores e mais diversificadas serão aquelas que podem acometer a psychê: ao olhar para dentro de si, pode-se encontrar a multiplicidade de afecções que assolam a alma e que marcam significativa diferença com aquelas do corpo, uma vez que a afluência não se dá pelo exterior, como é o caso das afecções do corpo, mas se origina ali mesmo, no interior de si. Segue-se, então, no tratado, uma distinção importante: se as doenças do corpo dão sinais como dores, calores ou palpitações, as doenças que acometem a alma são, por assim dizer, silenciosas e, por ocultarem do portador sua malignidade, roubam-lhe a percepção de que sofre de uma afecção. Imagem similar observamos na passagem supracitada de Platão, quando Timeu revela, acerca das doenças da alma, que a perda da harmonia leva o homem a alegrar-se em excesso ou sofrer em excesso, tornando-o incapaz de ver e ouvir as coisas de modo adequado e tendo, por conseguinte, seu raciocínio afetado. (Timeu, 86B-C).

Para pensar o tratamento de uma alma flagelada, Plutarco recomendará alguns cuidados e, entre as terapias recomendadas, como veremos, encontra-se o silêncio (sigé), apresentado como um potente ingrediente no combate às afecções das quais padece a alma. Porém, para que este possa agir, será necessária uma certa disposição de espírito.

Antes de nos enveredarmos pelo papel que será desempenhado pelo silêncio, busquemos entender aquela paixão para tratamento da qual ele se revela como particularmente eficaz, a saber, a adoleskhias, a tagarelice; destacando alguns de seus aspectos no âmbito de pensamento antigo, a fim de observar como ela surge enquanto um mal caracterizado por certas particularidades que fazem com que Plutarco sinta a necessidade de explicitar e propor um

\footnotetext{
${ }^{8}$ Trata-se do fragmento democrítico em que lemos: "se tu te abrisses, encontraria dentro de ti um grande e variado depósito e um tesouro de males, que não provêm de fora, mas têm fontes internas e nativas".
} 
tratamento para ela. Se o "falar" pode significar o imediato oposto do silêncio, o "tagarelar" será o seu extremo. Vejamos, então, como isto se processa.

\section{A TAGARELICE E TERAPIA PELO SILÊNCIO}

Quando buscamos compreender o modo como a paixão da tagarelice aparece nos textos anteriores a Plutarco, observamos que são muitos os contextos e diversas as perspectivas em que isso se dá. Examinando-as em conjunto, constatamos que algumas delas aparecerão também em Plutarco, enquanto outras não. Entre aquelas que reconhecemos como também presentes no Queronense, temos: a tagarelice referida ao desconhecimento e a falta de juízo quanto aos momentos oportunos para se exprimir sobre algo; a tagarelice referida à incapacidade de saber quando se deve silenciar; a tagarelice referida ainda ao fato de não se ter outro fim que não aquele de falar, ou seja, o falar por falar.

Ao tratarmos do silêncio, algumas reflexões sobre a que tipo de silêncio nos referimos se faz necessário. Em primeiro lugar, há que se pontuar que estamos tratando do silêncio no âmbito da vida humana, na qual o homem é o agente e o paciente que queremos analisar na relação sua com sigé. Dito isso, precisamos colocar em jogo algumas perspectivas desse silêncio. Podemos, por exemplo, falar de um aparente silêncio, sem voz, sem falas, mas a permanência de um diálogo interno consigo mesmo. Além disso, podemos pensar em um silêncio total, no qual teríamos não apenas a ausência de voz, mas também o "pensar em nada", em outras palavras, também uma mente silenciada. Na relação com o outro, podemos dizer que o silêncio é rompido quando se faz uso da palavra, desse modo, toda vez que haja fala, ainda que breve, o silêncio perde o lugar. Dizemos isso, pois, ao tratarmos da tagarelice, é preciso ter em mente o seu caráter de fala excessiva e, nesse sentido, se apresenta como o antissilêncio por excelência que aqui nos propomos a examinar.

Para buscarmos compreender o modo como a tagarelice aparece nos textos dos filósofos

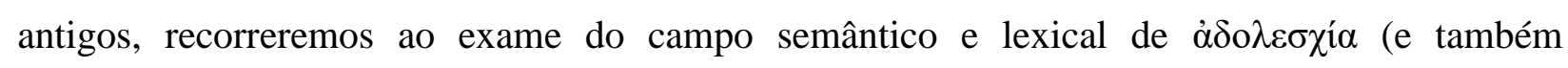

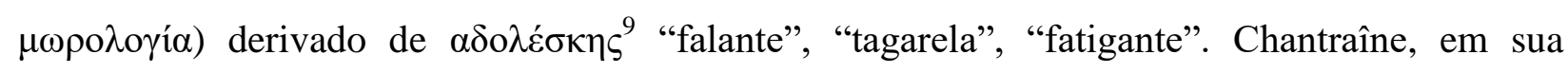
análise filológica elucida que: “o termo é atestado de maneira cômica, a propósito dos sofistas e

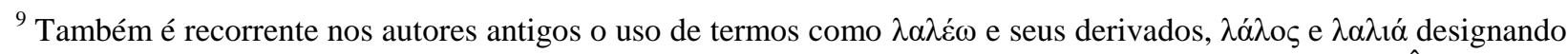
o "tagarelar", "falar muito" (p. 615) e também $\lambda \dot{\varepsilon} \sigma \chi \eta$, "conversação", "tagarelice" (p. 632). (CHANTRAÎNE, 1999). Insistimos, então, que na cultura grega o termo "tagarelice" admite uma polivalência de sentidos: desde a qualificação de uma conversa longa e profícua, até um falar inócuo, sendo este último caso o que nos interessa mais de perto no estudo do tema em Plutarco.
} 
de Sócrates" (CHANTRAîNE, 1999, p.20) (Cf. Eup fr. 353, Ar. Nu. 1485). Em Platão (R. 488,

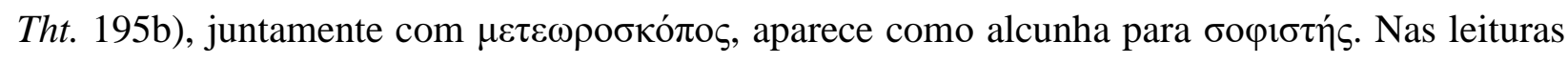
dos tratados de Plutarco a que nos dedicamos neste trabalho, observamos como uma tendência recorrente no autor: a associação do tagarela a uma figura indesejada e a visão da tagarelice como um mal a ser curado, em outras palavras, a $\alpha \delta o \lambda \varepsilon \sigma \chi i \alpha$ nos tratados plutarquianos que exploramos aparece sempre no âmbito do negativo. Contudo, ao examinarmos o termo em outros autores antigos, chama-nos a atenção o fato de que, muitas vezes, a "tagarelice" surgia não apenas como um modo de qualificar aquele que não sabe o momento oportuno e correto de guardar o silêncio ou mesmo que realiza seu discurso sem um fim em si, mas muitas vezes designava simplesmente o epíteto de falante, sem necessariamente designar um traço censurável.

Stones (1989, p. 146), avaliando o julgamento e o discurso irônico que levou à condenação de Sócrates presente na Apologia de Sócrates de Platão, assim traduz o tamanho da perda do filósofo para a cidade: “O homem mais tagarela de Atenas calou-se quando sua voz era mais necessária”. Ao chamar Sócrates de tagarela (talkative), no contexto em questão, Stones reproduz o adjetivo atribuído a Sócrates por vários de seus interlocutores nos diálogos platônicos e que não parece denominar necessariamente algo de negativo, mas apenas uma característica de Sócrates. A nosso ver, ao fazê-lo, é preciso atentar-se para o modo como adota-se um "rótulo" que, por vezes, não corresponde àquele que Platão parece ter atribuído a Sócrates: ao apontar a suposta adoleskhias de Sócrates, seus interlocutores distorcem a imagem do homem que, através da dialética, buscou trazer à luz o ser que se esconde por trás de cada parecer, a verdade por trás de conceitos, e tentam deslegitimar sua fala. Eles confundem o seu discurso com um logos sem medida, de um falar desprovido de pensamento e sem qualquer finalidade. Parece-nos não ser esse o caso de Sócrates. Em outras palavras, o adjetivo atribuído a Sócrates não parece representar o que de fato Sócrates é. Basta atentarmos para algumas das acusações que são apresentadas na Apologia de Sócrates, como, por exemplo, a de que ele teria "corrompido a juventude" e "difamado os deuses", para compreender logo que tais acusações mais são construções de seus acusadores que a conduta mesma de Sócrates.

Trata-se, então, de examinar o que de fato é tagarelice quando ela se traduz em algo reprovável e quando é tomada como tal sem o ser. Observado esse uso de adoleskhias, exploremos agora aquela que seria a noção que Plutarco parece querer nuançar: um páthos do qual a alma padece. O tema da tagarelice foi abordado pelo Queronense sobretudo em seu Sobre a tagarelice (De Garrulitate), tratado em que o autor busca expor os males oriundos daquele que não se habitua a ouvir e passa a produzir discursos sem medida e sem utilidade para quem ouve e 
para si mesmo, chegando a tornar-se motivo de risota e indesejado por seus concidadãos. A tese que norteia a obra é a de que a melhor virtude é o silêncio. Já nas primeiras linhas do tratado, Plutarco evidencia seu tom de repulsa à tagarelice. Assim, o lemos anunciar o mal do tagarela:

\begin{abstract}
É delicado e difícil para a filosofia empreender a cura da tagarelice. Pois seu remédio, a palavra, é feita para aqueles que ouvem, e os tagarelas não ouvem ninguém, já que estão sempre falando. Eis o primeiro mal contido na incapacidade de se calar: a incapacidade de ouvir. É uma surdez voluntária de homens que, creio eu, censuram à natureza o fato de terem apenas uma língua, embora tenham duas orelhas. Se Eurípides realmente fez bem de dizer a um ouvinte imbecil: "Eu não poderia encher o que nada segura, vertendo palavras sábias...", ou antes, inundando de palavras um homem que fala aos que não o ouvem e não ouve os que lhe falam. (Garr. 502B-D).
\end{abstract}

Em Das afecções do corpo e da alma, Plutarco defende que não caberá a um médico a cura para uma paixão da psychê, mas ao filósofo (An. corp. affect. Pei. 501B) e Plutarco já anuncia o fármaco capaz de empreender a cura de tal afecção: a palavra. Contudo, como já sinalizamos, na ótica de Plutarco quem é acometido por uma doença da alma tende a não reconhecer a própria enfermidade que se manifesta, no caso específico da adoleskhias, o mal estará na incapacidade de ouvir, que, como veremos, será o único meio de a alma ser angariada para a virtude. E quem seria o culpado pelo modo de padecer do tagarela? A surdez é oriunda de sua própria inobservância de que naturalmente a natureza lhe deu duas orelhas e apenas uma língua, num proporção matemática na qual se traduz claramente o ouvir mais e falar menos. Ao tomar os dizeres de Eurípides "eu não poderia encher o que nada segura, vertendo palavras sábias..." ${ }^{10}$ Plutarco parece recorrer a uma analogia presente em outros de seus escritos: o vaso como a psychê, que pode ou não estar preparada para receber algo de útil, tal como um vaso rachado não é capaz de comportar um líquido que lhe é vertido; as palavras, fármaco para o tagarela, não podem adentrar em sua alma, uma vez que esta está doente, quebrada. Não por acaso Plutarco dirá que a fala de Eurípides bem se traduz pela inutilidade de se tentar lançar palavras em um homem acometido pela adoleskhias e, como tal, não apenas não está habituado a ouvir os outros como, ao lançar seus discursos inúteis, os ouvintes não dão atenção.

Se são diversas as paixões que podem acometer a alma, a adoleskhias apresenta particularidades que a levam a um status particular, assim Plutarco ilustra as nuances desse páthos:

Entre as outras paixões e doenças, algumas são perigosas, outras são detestáveis e outras ainda são ridículas, mas os que sofrem de tagarelice calham todos os males: as pessoas

\footnotetext{
${ }^{10}$ Eurípides, frag. 899.
} 
zombam deles por suas histórias repisadas, detestam-nos pelas más notícias que espalham, ameaçam-nos pela sua incapacidade de guardar um segredo. Foi assim que se viu Anacarsis, que comera na casa de Sólon fazer a sesta com a mão esquerda repousada sobre as partes íntimas e mão direita sobre a boca, pois ele acreditava que a língua necessita de um freio mais forte, e acredita-o com razão. (Garr. 504F).

Se as diversas paixões podem ser alocadas no grupo de "perigosas", "detestáveis" ou "ridículas", no caso da adoleskhias todos os adjetivos podem lhe ser atribuídos, os concidadãos acabam criando aversão a tais pessoas, seja por suas histórias repetidas ou pelas desgraças que espalham, seja pela fama que logram de não serem capazes de guardar segredos. ${ }^{11}$ Segue-se uma imagem de Anacarsis ${ }^{12}$, na qual Plutarco, atribuindo maior força à mão direita, diz que esta estará mais bem utilizada se guardar a língua, que necessita ser refreada, ao passo que mesmo o símbolo da virilidade de Anacarsis se coloca em um patamar inferior. Como de costume, para reforçar a tese levantada, além da figura de Anacarsis, Plutarco desfilará, nas páginas seguintes do tratado, diversos exemplos e anedotas a fim de emular para o leitor os males que a tagarelice traz para a vida de alguém adoecido por tal paixão. Plutarco já anunciou no início do tratado a palavra como o fármaco capaz de curar a adoleskhias, mas pontuou a dificuldade de que tal fármaco possa agir no caso dos tagarelas. Como seria possível curar a alma de um falador desenfreado?

Uma série de exercícios será recomendada, tendo em vista indicar de que modo deve atuar a razão nesse ambivalente campo do discurso, fazendo pesar o fiel da balança para o papel fundamental que nesse processo será desempenhando por uma sorte de "aprendizagem do silêncio". Na ótica de Plutarco, a natureza do homem o revela como um ser capaz de aprender com seus próprios erros e acertos, com a justa avaliação de suas próprias ações, mas também com a consideração dos erros e acertos de outrem. Perguntamo-nos, então, em que medida uma espécie de aprendizagem do silêncio pode representar uma therapeia no horizonte da filosofia.

Para esta análise, será de grande relevância um exame da relação de simbiose que vemos ser gerida e tomar forma em Plutarco: a relação entre o silêncio / sigé e o discurso / palavra / logos. Tal análise se mostra pertinente, uma vez que na reflexão ética de Plutarco, um se processa em relação direta com o outro ou, dito de outro modo, a interdependência dos termos faz com que o estudo de um polo colabore na compreensão do outro de maneira fecunda.

$\mathrm{Na}$ tradição platônico-aristotélica, que, como vimos, Plutarco e tantos outros médio platônicos tentaram conciliar, a relação entre o discurso e alma de quem ouve parece ter

\footnotetext{
${ }^{12}$ Anacársis é um lendário dos sábios que compõem o Banquete dos sete sábios escrito por Plutarco.
} 
merecido especial atenção. Em tal esteira, a figura do terapeuta emerge como aquele que é dotado de certa técnica que o qualifica como tal. Mas se o ato de discursar está aberto tanto ao homem ordinário, quanto ao homem sábio, o que diferenciaria o uso das palavras feito por este do seu uso feito por aquele? Se o filósofo é por excelência o amante da sabedoria, há de se investigar mais de perto o modo como ele faz uso das palavras, e como percebe o quando e o como do falar e do calar no espaço da vida humana. Observamos, então, a relevância que neste âmbito recebe a noção de kairós, o momento oportuno ${ }^{13}$. O que observamos na economia do pensamento de Plutarco é o Kairos sendo um traço distintivo do sophos, razão pela qual é incentivado em quem almeja tornar-se sábio. Fiel da balança, o reconhecimento do kairos é fundamental para deliberar acerca de uma ou outra possibilidade; em virtude dele pode se avaliar, por exemplo, a necessidade de se temperar a conversação em um banquete na razão direta do estado de ânimo dos falantes, ao ponto de poder até mesmo abster-se do vinho em presença de uma boa conversa. Dessa forma, assim vemos Plutarco referir-se ao discurso:

Contudo, quando se reúnem homens com a vossa qualidade e que Periandro aqui juntou, não creio que haja necessidade de taças nem de vasos para servir o vinho, pois as Musas, ao colocarem à disposição de todos, como se fosse um grande vaso de mistura sem vinho, a conversa, que em si mesma contém o máximo de prazer, juntamente com boa disposição e seriedade, com ela despertam, irrigam e difundem a bondade, deixando jazer imóvel a maior parte do tempo o vaso de servir "em cima do vaso de mistura" precisamente aquilo que Hesíodo proibia de fazer na companhia de pessoas que apreciassem mais a bebida do que o diálogo. (Sept. Sap. 156D-E).

A palavra ${ }^{14}$ toma, então, o lugar do vinho, assegurando aos convivas efeitos semelhantes àqueles que se pretende obter com a bebida. $\mathrm{O}$ vinho tinha por objetivo tornar mais fácil a socialização dos convivas de modo que, mais abertos à conversação, realçassem os laços de amizade, estimulando a benevolência entre eles. O que observamos nessa fala destacada de Mnesífilo $^{15}$, é que naquele ambiente no qual se encontram vários sophoi, esta necessidade de vinho - que em geral dá fluxo às ideias nessas ocasiões e permite uma interação entre os participantes de um banquete -, nem sequer há, pois ali esse papel seria mais bem desempenhado pelos logoi dos convivas, pois ele que já conteria em si mesmo não apenas a capacidade de

\footnotetext{
${ }^{13}$ A ideia de aguardar o momento oportuno, Kairos, é objeto de atenção em vários autores da antiguidade, dentre eles Demócrito, Platão e Aristóteles.

${ }^{14}$ Como observa Entralgo (1958, p. 99-100), "a palavra do homem é divina e saborosa porque expressa e transmite, mas também por que persuade".

${ }^{15}$ Mnesífilo seria um ateniense e companheiro de um dos sete sábios, Sólon, e ao longo do diálogo tende a reforçar as ideias apresentados por este (Sept. Sap. 154d).
} 
proporcionar o prazer, que também se encontra no vinho, mas traria ainda aos convivas a

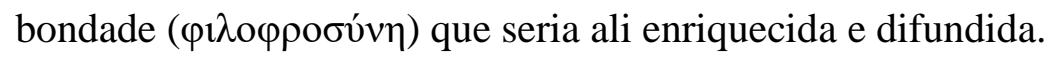

Em o Banquete dos sete sábios, Plutarco tenta reproduzir um ambiente de confraternização, onde os assuntos são tratados muitas vezes sem aprofundamento, tal como em uma conversa à mesa, de modo que a conversação vai de um a outro conforme a disposição dos participantes. Porém, alguns traços do diálogo entre os presentes no banquete promovido por Periandro nos chamam a atenção, tais como o respeito ao tema que está sendo tratado em cada momento e também a forma atenta da audição de cada um dos falantes: um por vez, sem interrupção. Quando, por exemplo, o sophos Sólon irá expor sua posição acerca da democracia, Plutarco não deixa de marcar que antes de proferir seu discurso, Sólon realiza uma breve pausa, como uma espécie de ação propedêutica para que o discurso que será proferido em seguida não seja irrefletido e corra o risco de ser feito em vão; em seguida, seguem-se comentários dos outros seis sophoi presentes acerca do mesmo assunto, sempre esperando que cada um tenha concluído sua exposição, sem nunca haver interrupção de um pelo outro (Sept. Sap. 152A). Assim, o discurso de um é uma ocasião para o exercício de um silêncio atento por parte dos demais convivas. Em outro passo do diálogo, no vai e vem dos assuntos tratados, é apresentada uma série de respostas dados pelo rei da Etiópia como objeto para a reflexão dos presentes ${ }^{16}$. Discordando das respostas dadas pelo rei, caberá a Tales proferir um logos acerca das questões e, mais uma vez, Plutarco observa que antes que Tales iniciasse sua exposição fez-se silêncio entre os presentes e, somente após ele, Tales tomou a palavra.

Temos aqui o exato oposto do comportamento que se observa em alguém acometido pelo mal da tagarelice ao se exprimir sobre uma questão. Ao acenar para o comportamento que alguém acometido pela adoleskhia e que deseja obter a sua cura dessa paixão, o Queronense adverte que não se deve "saltar incontinente sobre a palavra" (Garr. 512D), como que agradecido pela pergunta, mas deve-se antes analisar com atenção os modos de quem pergunta e que interesse ele tem. ${ }^{17}$ Se este realmente tem o interesse de saber algo sobre aquilo que pergunta, deve acostumar-se a ouvir a questão até o fim, esperando um momento, para ver se o

\footnotetext{
${ }^{16}$ As perguntas e respostas colocadas em jogo e que teriam sido dadas pelo rei da Etiópia, seriam as seguintes: "O que é a coisa mais velha? - O tempo. O que é a coisa mais extensa? - O universo. O que é a coisa mais sábia? — A verdade. O que é a coisa mais bela? — A luz. O que é a coisa mais comum? — A morte. O que é a coisa mais útil? — $\mathrm{O}$ deus. O que é a coisa mais prejudicial? - O demónio. O que é a coisa mais poderosa? — A Fortuna. O que é a coisa mais fácil? - O prazer" (Sept. Sap. 153A).

${ }_{17}$ Plutarco parece indicar a possibilidade de certa técnica de observação que permite com que se identifique determinados tipos de homens. Não apenas em Sobre a tagarelice, mas também em Como distinguir o bajulador do amigo, Como tirar proveito de seus inimigos e outros, observamos a recomendação de Plutarco de que uma afiada observação daqueles que nos cercam possibilita identificar certos padrões comportamentais que acabam por traduzir determinados estados de espírito.
} 
interrogador não deseja acrescentar nada e aproveitando, enquanto isso, para pensar numa boa resposta. Não se deve despejar uma avalanche de respostas, fervorosamente, sobre uma pergunta que sequer foi concluída, soterrando-a. Mas quem quer responder convenientemente deve esperar até entender bem o pensamento e a intenção de quem fez a pergunta, para que não se corra o risco de responder o que não cabe à pergunta, como diz certo provérbio lembrado por Plutarco "Eu reclamava baldes, eles recusavam tinas"18 (Garr. 512E-F).

Plutarco em Sobre a tagarelice, considera a adoleskhia um mal que pode ser tratado, mesmo considerando, em Das doenças do corpo e da alma, que as afecções da alma são de mais difícil tratamento que as do corpo. Ele reconhece que a prática do silêncio proporciona uma via terapêutica para se tratar a alma flagelada pelas paixões em geral e, particularmente, aquele que padece da tagarelice. O filósofo reflete que não se busca tirar da alma aquelas paixões que não nos são desagradáveis. As paixões passam a ser desagradáveis quando, examinando-as com a razão, compreendemos o que elas têm de nocivo e vergonhoso. Serão propostas, então, algumas etapas para o seu tratamento. Plutarco dirá que superamos as paixões pelo juízo e pelo treino, e que é necessariamente o juízo a primeira das etapas (Garr. 510D). Assim sendo, na terapia da paixão da adoleskhia, o primeiro passo ou remédio deve ser a reflexão acerca dos efeitos que ela, a tagarelice, produz: “querendo ser amados, são detestados, desejando agradar, são molestos, acreditando ser admirados, são motivo de chacota de todos, gastam sem nada ganhar, causam prejuízos aos seus amigos, trazem proveito aos seus inimigos, perdem-se a si mesmos." (Garr. 510 D). Nos efeitos próprios da tagarelice, Plutarco elenca os erros de julgamento daquele que, acometido por este mal, acaba por ter como foco algo diverso daquilo que de fato angaria: se deseja "amor", consegue "ódio", querendo ser "agradável” é "molesto", desejando "admiração", consegue o "deboche". Erram ainda ao inverter a lógica própria das relações entre amigos e inimigos: ajudam estes e prejudicam aqueles. Por fim, é a si mesmos que levam à perdição, dando mostra do quão distante está o objetivo do tagarela daquilo que de fato ele arremata.

Entrevê-se aqui que, na análise do tagarela que faz Plutarco, a sua vida na pólis, a sua relação com os outros é o terreno por excelência para a observância de sua doença, e aí estará também a porta de entrada para se reconhecer o mal que toma a sua alma. Ocorrem ali exatamente aqueles erros de julgamento que vimos Plutarco apontar como próprios daquele que sofre de uma doença da alma. Nota-se aqui um ambivalente movimento entre o momento que vai

\footnotetext{
${ }^{18}$ Esta era uma expressão comum no Império Romano, e servia para nuançar o comportamento daquele que não entende o que está em jogo em determinada discussão, ou seja, um mau ouvinte a quem se fala sobre "baldes", mas a contraparte entente "tinas" (TOSI, 1996. p. 395).
} 
do diagnóstico ao tratamento: o primeiro, aquele em que Plutarco, no papel de filósofo/terapeuta, identifica que alguém sofre do mal da tagarelice, e o segundo momento, aquele em que tem início o tratamento, momento este em que o próprio paciente é conduzido a reconhecer-se doente e a realizar um correto julgamento da patologia que o atinge, o que só é possível através da reflexão acerca dos seus efeitos sobre ele e das consequências que dele advêm. É, portanto, essa primeira reflexão o juízo dos males oriundos da tagarelice, a primeira etapa da terapia proposta por Plutarco. Mas essa etapa, a reflexão, parece ainda não ser suficiente para que o paciente alcance a de boa saúde da alma. O que ainda deve ser feito?

Como processo para a cura do mal da tagarelice, após a reflexão acerca dos males que a adoleskhia acarreta, o objeto passa a ser outro. Como segunda etapa nessa via terapêutica, Plutarco receita um comportamento que é o inverso das ações vergonhosas próprias do tagarela:

A segunda reflexão a que é preciso aplicar-se é a que tem por objeto o contrário: ouvir sempre, recordar e ter à disposição os elogios da discrição, o que há de venerável, sagrado e religioso no silêncio, e em que admiramos mais, apreciamos mais e julgamos mais sábios aqueles que concentram e limitam seus discursos, e assim reúnem muito espírito em poucas palavras. (Garr. 510E).

Se na primeira fase do tratamento Plutarco adverte sobre a necessidade de se observarem as consequências da tagarelice, na segunda fase, deve-se buscar contemplar exatamente o estado oposto daquele, de modo que o sentido da audição, tão ausente nos tagarelas, passa vir a ocupar o lugar antes ocupado pela fala. Reconhece-se aqui a tese que examinamos no tópico consagrado ao exame da relação entre "silêncio e virtude, aquela que afirma serem os ouvidos a única porta de entrada para a alma do ouvinte" (Aud. 38b), de modo que, se é possível uma therapeia para aquele que sofre do mal de tagarelice, ela deverá passar justamente pelo aprendizado da audição, e, logo do silenciar. Trata-se não do silêncio como ausência de logos, mas do silêncio que oferece ao logos um ambiente favorável para acolher as palavras lançadas à alma. Plutarco recorre ainda àquele procedimento que consiste em observar a vida de outrem como um espelho no qual o homem pode refletir sobre o seu próprio modo de vida, sugerindo que se deva ter na memória justamente a boa reputação que gozam os homens mais discretos. O silêncio irá aparecer, então, como campo de exercício para aquele que quer se livrar do mal da tagarelice. Plutarco qualifica o silêncio como "venerável", "sagrado" e "religioso"19. Essa mesma ideia aparece mais uma vez neste tratado, quando o Queronense sentencia que aos seus olhos "se são os homens que nos ensinam a falar, são os deuses que nos ensinam a calar, quando aprendemos

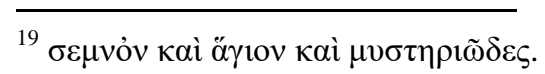


com eles o silêncio nas cerimônias e nos mistérios" (Garr. 505 F). Tratar-se-ia de reconhecer o primado do silêncio sobre a fala, elegendo-o como a parte melhor da dupla composta por "falar" e "calar". Os cultos de natureza mistérica surgem como lugar de prática do silêncio ${ }^{20}$, que será também considerada como tão necessária à cura da tagarelice. Entre o silêncio e a tagarelice, a reflexão de Plutarco se apresenta como uma via para a therapeia da alma.

Como registro da análise do silêncio preconizada por Plutarco, vemos também em Como ouvir que ele elege o ouvido à posição de órgão por excelência da sabedoria ( $A u d$. 38B), uma vez que este é tido pelo filósofo como um canal de acesso à alma e único meio eficaz para conduzi-la ao status de virtuosa. Por isso o Queronense se preocupa com as palavras que os adultos dirigem à alma das crianças, e adverte para que aquelas não sejam licenciosas, mas, antes, úteis. É como se, uma vez flagelada por palavras indevidas, a alma padecesse, se deformasse, e se constituísse assim um obstáculo para a virtude. Era um costume em sua época que as crianças fossem beijadas, nas orelhas tocadas, o que, segundo Plutarco, tinha por consequência o convite a se amar aqueles que nos beneficiam pelos ouvidos, canal de acesso à alma. Ele chegou ao ponto de dizer que um jovem que não gozasse do sentido da audição seria mais propenso ao vício e jamais teria sua alma conquistada para a virtude. Tal propósito pode nos soar estranho, mas não se considerarmos que tal ordem de questões era de fundamental importância em um tempo em que a oralidade ainda imperava, e que a experiência da escuta ainda prevalecia sobre aquela da leitura, e, além disso, vale lembrar que em sua época era proeminente no mundo greco-romano, e em todas as suas formas e âmbitos, a arte retórica.

\section{CONCLUSÃO}

Como um filósofo-médico, Plutarco quer proporcionar aos homens a possibilidade de extrair do pharmakon-palavra os benefícios para o bem viver. E nesse processo o recurso ao silêncio emerge como um potente ingrediente. Sob a forma de prescrições, é possível identificar algumas constantes que caminham passo a passo com sua concepção do bem viver, delineando a função propedêutica da razão na orquestração das paixões. É nesse quadro que o escutamos dizer que a tagarelice deve ser vencida pelo hábito e pela atenção prestada às respostas que damos. Plutarco diz que admiramos os que através de pouca fala ou silêncio potencializam suas

\footnotetext{
${ }^{20}$ Tal caráter do silêncio é também evocado na admiração de Plutarco pelos povos que, através de tais ritos mistéricos, habituavam os homens ao uso do silêncio, conforme lemos em seu Da educação das crianças. (Lib. Educ. 10 E-F). Reconhece-se que, ao pensar a paideia, Plutarco vê no silêncio um caráter formador e, enquanto tal, ele não deve ser negligenciado na economia de um discurso sobre a educação das crianças.
} 
palavras de valor. O que esses homens apresentam de "sentencioso e penetrante" em suas réplicas provém de um longo silêncio. A esses homens, louvando-os, Platão os chama de "hábeis arqueiros", por falarem restrita e concisamente (Garr. 510 F). Consonante a Plutarco podemos reconhecer o desejo do filósofo de emular no espírito de seu leitor a ideia de que a breviloquência é mais desejada e venerável que um falar desenfreado. Ao observarmos a relação entre silêncio e discurso, um dos traços dos Sete Sábios é exatamente aquele de produzir sentenças breves, mas carregadas de sentido. No contexto do Banquete dos sete sábios observamos a ação mediadora do kairos temperando a conversa na medida correta, e proporcionando, assim, um ambiente em que o diálogo se opera harmonicamente da fala ao silêncio e vice e versa. Como observamos naquele momento, a tagarelice no sentido nefasto em que aparece nos textos de Plutarco não terá espaço no ambiente da conversação entre homens sábios.

Para nuançar a importância da atenção que se deve dar às respostas que oferecemos, Plutarco lembra que a Pítia ${ }^{21}$ costumava oferecer oráculos antes mesmo da pergunta, uma vez que o deus que ela honra, citando Heródoto, "ouve o mudo e escuta a quem nada diz",22 (кaì

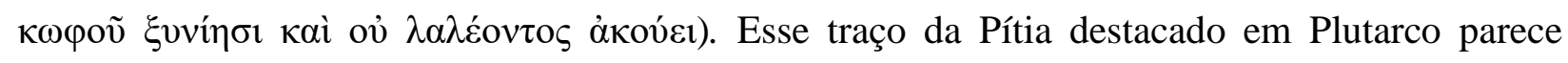
indicar que no contexto religioso o silêncio emerge como um traço comum a diversos ritos e práticas. A própria Pítia não precisa que a palavra seja proferida para que possa proferir seus oráculos. Tal fato é considerado em passagens em que Plutarco faz notar que o silêncio figura no mundo dos "deuses" como sendo mais correto que o uso das palavras, o que não parece ser o caso entre os "homens". E se à sacerdotisa é possível dar respostas sem que lhe seja necessária a formulação de uma pergunta, contrariamente ocorre com o tagarela, que ao submeter-se à terapêutica, deve se exercitar em aguardar pacientemente o término da apresentação de uma questão, antes de se pronunciar a seu respeito.

Desejoso de suscitar no espírito do tagarela a melhor disposição para se curar de seu mal, Plutarco considera o caráter ambivalente da língua. Conta que Pítaco, ao receber as ordens do rei do Egito para que retirasse de uma vítima aquelas que seriam a melhor e a pior parte, retirou-se a

\footnotetext{
${ }^{21}$ Sacerdotisa do templo de Apolo, em Delfos, onde o próprio Plutarco veio a ser sacerdote (Sobre os oráculos na antiguidade, ver Morgan, 1990).

${ }^{22}$ Trata-se de uma passagem de As histórias (HERODOTE, 1850), em que lemos: “on ne connaît que la réponse de l'oracle de Delphes, et l'on ignore quelle fut celle des autres oracles. Aussitôt que les Lydiens furent entrés dans le temple pour consulter le dieu, et qu'ils eurent interrogé la Pythie sur ce qui leur avait été prescrit, elle leur répondit ainsi en vers hexamètres: 'Je connais le nombre des grains de sable et les bornes de la mer ; je comprends le langage du muet; j'entends la voix de celui qui ne parle point. Mes sens sont frappés de l'odeur d'une tortue qu'on fait cuire avec de la chair d'agneau dans une chaudière d'airain, dont le couvercle est aussi d'airain'.” (Hist. I, 47). Citado também em Garr. 512E.
} 
língua (Garr. 506D), exatamente por ser ela a responsável, ao mesmo tempo, pelos maiores bens (um logos fecundo) e os pelos maiores males (a fala incontinente, que pode levar à desgraça). Contrapondo então a figura do tagarela com a dos sophos, observamos nestes a regulação do logos e do silêncio sempre sendo mediada pelo kairos, no qual este correto cálculo do momento oportuno de falar e calar possibilita que as respostas e considerações feitas sejam de fato úteis e fecundas, não dando espaço para um falar sem medidas ou para uma audição surda.

Além disso, o uso adequado do logos é um bom guia para o bem viver. Plutarco diz em Como ouvir que, de fato, devemos desejar melhorar nossa vida por meio das palavras e que é desejando isto que devemos, por exemplo, ir ao teatro como se fôssemos assistir a uma lição ou aula. Da mesma forma, deve-se julgar uma audiência, não apenas por ela mesma, mas também pelos efeitos ou frutos que ela gera em mim, o que pode se verificar se "boas resoluções e sentimentos elevados se tornaram mais firmes, se brotou em si o entusiasmo para a virtude e o bem" (Aud. 42B). Por meio de uma analogia, Plutarco diz que assim como passamos a mão na cabeça para examinar o resultado de uma ida ao barbeiro, devemos, após uma audiência, verificar se também houve uma melhoria, nesse caso, uma melhoria na alma, pois, como dizia Ariston $^{23}$ “o banho e o discurso que não purificam, não servem”. Se o discurso tem o poder de tornar a vida melhor, ele só poderá realizar essa sua potência se contar com sua contraparte, a saber, o correto uso do silêncio.

O silêncio aparece nesse contexto não apenas como aquele ingrediente capaz de tornar eficaz o fármaco-palavra, mas também como uma espécie de exercício, com o fim de estimular o hábito, exercício ao qual se lança aquele que deseja vencer a adoleskhia. Entre as prescrições que Plutarco enumera em Sobre a tagarelice, destacamos 1) a recomendação de que em um conselho de vizinhos, habitue-se a calar-se até que todos tenham se pronunciado (Garr. 511F); 2) a que diante de uma pergunta, o tagarela se habitue a realizar uma pausa antes de dar a sua resposta, a fim de assegurar-se de que aquele que pergunta não irá acrescentar nada a mais em sua pergunta; 3) que se limite a resposta de acordo com o interesse específico de quem pergunta (Garr. 512D); 4) que o tagarela deve evitar também aqueles assuntos ou palavras que mais lhe estimulam a falação (Garr. 513E). Cada um desses exercícios buscam fazer com que o silêncio se torne algo habitual na vida daquele que é acometido pela tagarelice.

Portanto, podemos reconhecer em Plutarco pelo menos duas potências do silêncio como via para a therapeia da alma tomada pela paixão da tagarelice. Uma primeira é aquela em que ele

\footnotetext{
${ }^{23}$ Filósofo estóico (BABUT, 2003, p. 203).
} 
opera sobre o pharmakon-palavra, incrementando-o e fazendo com que este fármaco tenha, de fato, um poder reparador para a alma. Uma segunda é aquela em que o silêncio emerge como um exercício terapêutico capaz de criar o hábito do silêncio, hábito que permite com que o homem aprenda a dispor do devido tempo de reflexão antes de falar, observando de perto os efeitos que esse hábito produz na sua vida cotidiana. Como Plutarco observa, são geralmente mais graves as consequências do que dizemos do que daquilo que deixamos de dizer. Elogia-se não o silêncio de quem calando consente, mas de quem calando habitua-se a perceber o justo e melhor momento de dar livre curso às palavras.

\section{REFERÊNCIAS}

ARISTÓTELES. Metafísica. v. I, II, III. 2. ed. Ensaio introdutório, tradução do texto grego, sumário e comentários de Giovanni Reale. Tradução portuguesa Marcelo Perine. São Paulo: Loyola, 2002.

BABUT, D. Plutarque et le Stoicisme. Paris: Presses Universitaires de France, 2003.

CHAINTRAINE, P. Dictionnaire étymologique de la langue grecque: Historie de mots. Paris: Klincksieck, 1999.

CHAUÍ, M. Introdução à história da filosofia: as escolas helenísticas. v. II. São Paulo: Companhia das Letras, 2010.

DIELS, H; KRANZ, W. (hrsg.). Die Fragmente der Vorsokratiker. Griechisch und Deutsch. Bd. 2. Zürich: Weidmann, 1996, 18a edição a partir da 6a edição de 1952.

ENTRALGO, Pedro. La curación por la palabra en la Antigüedad Clásica. Madrid, Revista de Occidente, 1958.

GAZOLLA, R. O ofício do filósofo estoico: o duplo registro do discurso da Stoa. São Paulo: Loyola, 1999.

HERODOTE. Histoire. Trad. du grec par Larcher; avec des notes de Bochard, Wesseling, Scaliger. et al. Paris: Charpentier, 1850.

HOMERO. A Ilíada. Tradução Haroldo de Campos. Introdução e organização de Trajano Viera. 2 v. (bilíngue). São Paulo: Arx, 2003.

MACIEL, S. M. Mútuas implicações: prazer e intelecto no Filebo. Boletim do CPA, Campinas, $\mathrm{n}^{\mathrm{o}}$ 15, jan./jun. 2003. p. 191-204.

MORGAN, Catherine. Athletes and oracles. Cambridge: Cambridge University Press, 1990.

OZANAM, Anne-Marie. Préface. In: PLUTARQUE. Vies parallèles. Traduction d'Anne-Marie Ozanam. Paris: Gallimard, 2001. (Coll. Quarto). 
PLATÃO, Timeu-Crítias. Tradução do grego, introdução e notas. Rodolfo Lopes. Coimbra: Centro de Estudos Clássicos e Humanísticos Editor, 2011.

PLUTARCO. Como ouvir. Tradução de João Carlos Cabral Mendonça. São Paulo: Martins Fontes, 2003.

PLUTARCO. Obras morais. Da educação das crianças. Tradução de Joaquim Pinheiro. Coimbra: CECH, 2008.

PLUTARCO. Obras morais. O banquete dos sete sábios. Tradução de Delfim F. Leão, Coimbra: CECH, 2008.

PLUTARCO. Sobre a tagarelice e outros textos. Tradução de Mariana Echalar. São Paulo: Landy, 2008.

PLUTARCO. Vidas paralelas: Alexandre e César. Apresentação de Voltaire Schilling, Tradução de Julia da Rosa Simões. Porto Alegre: LP\&M, 2005.

PLUTARQUE. Ouvres morales. Collection des Universités de France. Tome II. Paris: Les Belles Lettres, 2003.

PLUTARQUE. Vies parallèles. Traduction d'Anne-Marie Ozanam. Paris: Gallimard, 2001. (Coll. Quarto).

REALE, G. História da filosofia antiga, V. (Léxico). Tradução Henrique Claudio de Lima Vaz e Marcelo Perine. São Paulo: Loyola, 2001.

REALE, Giovanni. Renascimento do platonismo e do pitagorismo. Tradução Henrique Claudio de Lima Vaz. São Paulo: Loyola. 2008.

RUSSEL, D. A. Plutarch. 2n edition. London: Bristol Classic Press, 1972.

SCHILLING, Voltaire. Apresentação. In: PLUTARCO. Vidas paralelas: Alexandre e César. Apresentação de Voltaire Schilling, Tradução de Julia da Rosa Simões. Porto Alegre: LP\&M, 2005.

SENECA, L. A. Dell'ira libri III. Tradução, introdução, texto e notas de Adriana Bortone Poli. Roma: dell'Ateneo \& Bizzarri, 1977.

STONES. I. F. The Trial of Socrates, Southern Humanities Review, v. XXIII, n. 3, Summer 1989, p. 264-267.

TOSI, Renzo. Dicionário de sentenças latinas e gregas. São Paulo: Martins Fontes, 1996.

ZIEGLER, K. Plutarco. Traduzione di Maria Rosa Zancan Rinaldini. Brescia: Paideia, 1965. 